\title{
Ceramic Dental Implants: A Literature Review
}

\author{
Jodat Askari*, Mohammad Iqbal and Salim Ateyah \\ Assistant Professor, Prosthodontics, Rakcods, UAE \\ Received: November 02, 2017; Published: November 13, 2017 \\ *Corresponding author: Jodat Askari, Assistant Professor, Prosthodontics, Rakcods, UAE, Tel: 92301-8211252; Email: jodataskari@yahoo.com
}

\begin{abstract}
Background: Titanium, also known as conventional implant is the gold standard material for dental implant. The reason behind this is their outstanding biocompatibility, adequate mechanical properties and beneficial results. When exposed to air, titanium instantly develops a stable oxide layer, which forms the basis of its biocompatibility leading to a better Osseointegration [1-3]. Zirconia (ZrO2) is a ceramic material with sufficient mechanical properties for manufacturing of medical devices [2] Zirconia-based implants were introduced into dental implantology as a substitute to titanium implants. Zirconia seems like an appropriate candidate for implant material due to its tooth-like color, its biocompatibility and its mechanical properties and low plaque affinity [1,4] The major drawback of titanium is its gray color. In various situations, there could be an unaesthetic display of the metal components due to lack of soft tissue height over the implant level this can also take place following soft tissue recession and marginal bone loss [4,5]. Zirconia opacity is very helpful in unfavorable clinical situations. RadioOpacity can aid evaluation during radiographic controls. Frameworks of Zirconia are made using computer-aided design/manufacturing (CAD/ CAM) technology [5].

Aims of this Study: The aim of this study is to review clinical and research articles conducted on zirconia dental implants, observe their success rate with a minimum follow up of 5years \& compare them with titanium dental implants.

Materials and Methods: A literature search was performed of the Pub Med database using the following key words: 'zirconia,' 'zirconia implant, 'zirconia versus titanium. The searches were limited to articles in English published from 2003 to 2016.

Results: A total of 4 articles matched the criteria of a minimum 5year follow up study. A cumulative success rate of $92.2 \%$ was observed.

Conclusion: Literature search showed that the success and longevity of dental implants strongly depend on surface characteristics and adequate osseointegration. And that the use of right size, shape, length and diameter of the implant in optimal loading conditions would increase the chances of successful implant placement. Although it also highly depends on that the right technique is being followed by the operator. Some of the properties of zirconia seem to be suitable for making it an ideal dental implant, such as biocompatibility, osseointegration, favorable soft tissue response and aesthetics due to light transmission and its color. Zirconia can prove a feasible alternative in replacing titanium. A need for more clinical trials concerning resistance to failure in long-term is of high importance.
\end{abstract}

Key words: Zirconia; Zirconia implant; Zirconia versus titanium

\section{Introduction}

Dentists and dental specialists use significant clinical skills in an attempt to deal with the consequences of complete and/or partial edentulism [6]. The therapy of completely and partially edentulous patients with dental implants is an accepted and eminent treatment modality [2]. Zirconia is one of the most capable restorative biomaterial, due to its highly positive mechanical and chemical properties appropriate for medical application. Zirconia ceramics (ZrO2) are becoming a widespread biomaterial in dentistry and dental implantology [2]. Titanium has been the preference for dental implants for the past many years. Its properties and characteristics have been found to be most fitting for the success of implant treatment. But lately, zirconia is gradually rising as one of the materials to reinstate the gold standard of dental implant, i.e., titanium [1]. Dental implants are biocompatible metal anchors surgically placed in the jaw bone beneath the gums to hold an artificial crown where natural teeth are missing.

Using the root form implants which are the nearest in shape and size to the natural tooth root, the non-union bone healing stage generally varies from three months to six or more. During this period, osseointegration occurs. The strong sustainability of the implant is due to the bone growing in and around it, to which a superstructure will be attached later on by either cementation or screw-tightening retaining technique $[7,8]$. Since the material composition and the surface topography of the implants play a fundamental part in osseointegration, various chemical and physical surface modifications have been developed in order to decrease the 
time of osseous healing, and it was observed that increased surface roughness of dental implants lead to greater bone apposition and reduced healing time [9].

\section{Review of Literature}

Implants are traceable to ancient Egyptian and south American civilization around 1000AD [10]. Where carved seashells and/or stones were placed into human jaw bone to replace missing teeth [11]. With the 18th century being the start of Endosseous oral implantology [10]. The modern dental implant history as we know it started during World War II when in the years of service in the army, Dr. Norman Goldberg thought about dental restoration using metals that were used to replace other parts of the body. Later on in 1948, in association with Dr. Aaron Gershkoff, they produced the first successful sub-periosteal implant. This success formed the foundation of implant dentistry in which they were pioneers in teaching techniques in dental schools and dental societies around the world [10]. One of the most significant developments in dental implantology occurred in 1957, when a Swedish orthopedic surgeon by the name of Per-Ingvar Brånemark began studying bone healing and regeneration and discovered that bone could grow in proximity with the titanium (Ti), and that it could effectively be adhered to the metal without being rejected. Therefore, Brånemark called this phenomenon 'osseointegration', and he carried out many further studies using both animal and human subjects $[12,13]$. The development of modern ceramics started in 1992; and from that time on, dental implant companies have incorporated ceramic surface treatments and ceramic-like elements to implants with the purpose of further enhancing Osseointegration [10].

\section{What Are Ceramic Implants}

All-ceramic dental implants were introduced in dental implantology as a substitute to titanium implants. One of the main reasons to find an alternative material to titanium was sensibilization; it is the possible release of metallic ions, and allergy to this material, as reported in some studies [5]. The first ceramic material that was used in the past for dental implants was aluminium oxide. This material showed good osseointegration but it did not have sufficient mechanical properties for long-term loading [5]. More recently, new generation ceramic materials such as zirconia were introduced. Zirconia is characterized by more favorable mechanical properties (high flexural strength (900$1200 \mathrm{Mpa}$ ), hardness (1200Vickers), and Weibull modulus [1315] than aluminium oxide. In addition, this biomaterial has a high biocompatibility and low plaque adhesion $[14,16]$. Zirconia exists in three phases, Monoclinic (M), Cubic (C) and Tetragonal (T), depending on temperature. M-phase is fragile at room temperature, and therefore requires stabilization to prevent Tetragonal (T)-toMonoclinic(M) phase transformation in technical applications. A stress-induced transformation toughening mechanism improves the mechanical strength of zirconia, rendering it more suitable as a dental implant material.

Yttria (Y203) is used as a general stabilizer for maintaining the T-phase of zro2. Y203-stabilized tetragonal zirconia polycrystals (Y-TZP) have high strength, toughness, and biocompatibility, and elicit biological responses that are similar to those induced by titanium. Therefore, Y-TZP is considered as a potential titanium alternative $[11,17]$. One unique feature of zirconia is its crack resistance, also called transformation toughening. This phenomenon increases the fracture toughness of the material and might be the explanation for the so far excellent clinical survival rates. Besides sound survival rates, the goal of an implant treatment is to achieve a harmonious reconstruction that cannot be distinguished from natural teeth by the naked eye. This is of particular importance in the challenging and most exposed anterior region of the jaws. The type of zirconia used in dentistry is partially stabilized tetragonal zirconia poly-crystals. This specific type of zirconia exhibits very high fracture toughness, i.e. Resistance towards crack propagation, through a phenomenon called "transformation toughening" [18].

\section{Materials and Methods}

A literature search was performed of the Pub Med database using the following key words: 'zirconia,' 'zirconia implant,,'zirconia versus titanium'. The searches were limited to articles in English published from 2003 to 2016.

\section{Results}

Table 1 shows only 4 articles that matched the criteria of minimum 5-year follow up. With a total of 1055 implants inserted to 82 of them failing. This gave us a cumulative success rate of $92.2 \%$. Other result is the comparison of Titanium and Ceramics. The Table 2 shows the differences between them. Zirconia comes as a one piece, with the implant and abutment fused together being easier to maintain. Titanium can come either one piece or two piece, with implant and the abutment separately but harder to maintain. The microgap between implant and abutment in two piece may cause plaque accumulation. The margins of Zirconia and Titanium are at the gingival level and bone level respectively. Titanium can undergo corrosion and might cause allergic reactions. Surface roughness of Zirconia is smooth with less osteointegration compared to titanium due to it having a rough surface.

Table 1: Success Rate with minimum 5 year follow up.

\begin{tabular}{|c|c|c|c|c|c|c|}
\hline Article: & $\begin{array}{c}\text { Year of } \\
\text { Publication: }\end{array}$ & Follow up after: & $\begin{array}{l}\text { Implants } \\
\text { inserted: }\end{array}$ & $\begin{array}{c}\text { Implants } \\
\text { succeeded: }\end{array}$ & Implants failed: & Success rate: \\
\hline Zembic [12] & 2015 & 11 years & 31 & 29 & 2 & $96.3 \%$ \\
\hline Oliva [5] & 2010 & 5 years & 831 & 789 & 42 & $95.0 \%$ \\
\hline Grassi [34] & 2015 & 5 years & 32 & 30 & 2 & $93.8 \%$ \\
\hline 4)Roehling & 2016 & 7 years & 161 & 125 & 36 & $77.3 \%$ \\
\hline
\end{tabular}


Table 2: Comparison between Zirconia and Titanium.

\begin{tabular}{|c|c|c|}
\hline & Zirconia & Titanium \\
\hline One piece or two piece & Only one Piece & One-Piece or Two Piece \\
& Two piece can be corrected [28] \\
\hline Adherence to Plaque & Which gives a little room for error [20] & Adheres to Plaque [ 32] \\
\hline Fracture Tendency & Does not adhere to plaque [32] & No or less prone to fractures [28] \\
\hline Fracture Tendency & It may fracture [20] & At bone level [32] \\
\hline Margin & It may fracture [20] & Metal corrone to fractures [28] \\
\hline Maintenance & At gingival level [32] & May have allergic reaction [32] \\
\hline Corrosion & Easier to maintain [32] & More [26] \\
\hline Allergic Reactions & Resistant to Corrosion [26] \\
\hline Osseo-integration & No allergic reaction [32] & Rough(more bone apposition) [20] \\
\hline Surface Roughness & Less [26] & Smooth [20] \\
\hline
\end{tabular}

\section{Discussion}

\section{Success Of Implants}

The success and longevity of dental implants are strongly governed by surface characteristics. There are certain factors that successful implants must possess to accommodate the ossteointegation. They are:

a. Biological compatibility not to be toxic to surrounding hard and soft tissues,

b. Mechanical compatibility to smooth transfer the stress between the placed implant root and receiving hard tissue, and

c. Morphological compatibility to accommodate the surface rugophilicity and promote bony cell growth [7].

\section{Criteria of Success}

\section{Albrektsson}

a) Individual unattached implant that is immobile when tested clinically

b) Radiography that does not demonstrate evidence of periimplant radiolucency

c) Bone loss that is less than $0.2 \mathrm{~mm}$ annually after the implant's first year of service

d) No persistent pain, discomfort or infection.

e) By these criteria, a success rate of $85 \%$ at the end of a 5 year observation period and $80 \%$ at the end of a 10 year period are minimum levels for success [10,19-21].

\section{Reasons Of Failure( In Mentioned Articles)(And Others)}

Zembic. Mentioned the loosening of abutment screws as a reason to failure

A. Oliva [11] stated implants failed due to placement after simultaneous sinus elevation and patients being smokers.

B. Grassi [22] observed that implants failed after immediate loading

C. Roehling [2] were conducting a research with different implant diameters $(3.00 \mathrm{~mm}, 4.00 \mathrm{~mm}, 5.00 \mathrm{~mm})$.
They observed that the implants with $3.00 \mathrm{~mm}$ had. Absence of signs of marginal bone loss around implants surface indicates maintained integration between the implant fixture and the surrounding bone [16]. However, the finding of periimplant bone remodelling must be carefully considered because the marginal bone loss which may be detected around implants after beginning of function should be distinguished from the bone loss that is affected by one or more of the following factors:

a) Traumatic surgical technique,

b) Excessive loading conditions,

c) Location, shape, and size of the implant abutment microgap and its microbial contamination,

d) Biologic width and soft tissue considerations,

e) Periimplant inflammatory infiltrate,

f) Implant and prosthetic components micromovements,

g) Repeated screwing and unscrewing [10].

\section{Other Possible Reasons of Failure}

Systemic risk factors can increase the risk of treatment failure or complications, but very few absolute contraindications to dental implant treatment are defined. Conditions that increase the risk of failure include but are not limited to smoking and endocrine disease (tooth and implant loss related to vasoconstriction and tissue hypoxia), osteoporosis (reduction in alveolar bone density and mass due to the altered bone metabolism), microbial and immune-inflammatory factors, cardiovascular disease, myocardial infarction, cerebrovascular accident, severe bleeding issues, and chemotherapy In general, these failure rates have been associated with poor bone quality and/or quantity which leads to poor anchorage and stability of the implant $[10,21]$.

a) Implants failed if the width of the attached gingival is $\leq 2 \mathrm{~mm}$. Other studies have shown that a thin or absent masticatory gingival was associated with bleeding on probing and a significantly greater mean loss of alveolar bone [22].

b) Silk sutures were less likely to support bacterial colonization than other suture materials which minimizes the 
chance of odontogenic infections.Use of polyglactin 910 was associated with a higher incidence of early loss of implants [22].

c) Smoking can inhibit blood flow to the bone may lead to disrupted Osseointegration [22].

d) A non-infectious process resulting in bone resorption, for which the term "aseptic loosening" is used [17].

\section{i. Titanium}

Titanium has a good record of being used successfully as an implant material and this success with titanium implants is credited to its excellent biocompatibility due to the formation of stable oxide layer on its surface $[19,23]$. The commercially pure titanium (cpti) is classified into 4 grades which differ in their oxygen content. Grade 4 is having the most $(0.4 \%)$ and grade 1 the least $(0.18 \%)$ oxygen content. The mechanical differences that exist between the different grades of cpti is primarily because of the contaminants that are present in minute quantities. Iron is added for corrosion resistance and aluminum is added for increased strength and decreased density, while vanadium acts as an aluminum scavenger to prevent corrosion.. Because of the high passivity, controlled thickness, rapid formation, ability to repair itself instantaneously if damaged, resistance to chemical attack, catalytic activity for a number of chemical reactions, and modulus of elasticity compatible with that of bone $\mathrm{o}$, Ti is the material of choice for intraosseous applications [11].

\section{ii. Zirconia}

Zirconia was used for dental prosthetic surgery with endosseous implants in early nineties. Ceramic implants were introduced for osseointegration, less plaque accumulation resulting in improvement of the soft tissue management, and aesthetic consideration as an alternative to titanium implants. Apart from there being the esthetic issue due to gray color of titanium which becomes more prominent when the soft tissue condition is not optimal and it becoming visible through the mucosa [11] It may also cause a greyish discoloration of the peri-implant mucosa where as Ceramic abutments are reported to reduce soft tissue shadowing due to their color and enhanced translucency which may lead to optimal esthetic results in combination with all-ceramic crowns [18]. Plaque accumulation and bacterial colonization on titanium is also one of the bigger drawbacks [24-34].

\section{Conclusion}

Literature search showed that the success and longevity of dental implants strongly depend on surface characteristics and adequate osseointegration. And that the use of right size, shape, length and diameter of the implant in optimal loading conditions would increase the chances of successful implant placement. Although it also highly depends on that the right technique is being followed by the operator. Many of the properties of zirconia seem to be suitable for making it an ideal dental implant, such as biocompatibility, osseointegration, favourable soft tissue response and aesthetics due to light transmission and its color. Zirconia could be a feasible alternative in replacing titanium. A need for more clinical trials concerning resistance to failure in long-term is of high importance.

\section{References}

1. Apratim A, Eachempati P, KrishnappaSalian KK, Singh V, Chhabra S, et al. (2015) Zirconia in dental implantology: A review. Journal of International Society of Preventive \& Community Dentistry 5(3): 147-156.

2. Depprich R, Zipprich H, Ommerborn M, Naujoks C, Wiesmann HP, et al. (2008) Osseointegration of zirconia implants compared with titanium: an in vivo study. Head \& Face Medicine 4: 30.

3. Deeksha S, Regish K, Anoop N, Prithviraj D (2012) A systematic review of zirconia as an implant material. Indian Journal of Dental Research 23(5): 643-649.

4. Ramesh T, Gangaiah M, Harish P, Krishnakumar U, Nandakishore B (2011) Zirconia Ceramics as a Dental Biomaterial -An Over view.

5. Oliva J, Oliva X, Oliva JD (2010) Five-year success rate of 831 consecutively placed Zirconia dental implants in humans: a comparison of three different rough surfaces. Int J Oral Maxillofac Implants 25(2): 336-44.

6. Özkurt Z, \&Kazazoğlu E (2011) Zirconia Dental Implants: A Literature Review. Journal of Oral Implantology 37(3): 367-376.

7. Velazquez-Cayon R, Vaquero-Aguilar C, Torres-Lagares D, JimenezMelendo M, Gutierrez-Perez J (2012) Mechanical resistance of zirconium implant abutments: A review of the literature. Medicina Oral Patología Oral y CirugiaBucal 17(2): 246-50.

8. Gupta S (2016) A Recent Updates on Zirconia Implants: A Literature Review. Dent Implants Dentures 1: 113.

9. Borgonovo AE, Censi R, Vavassori V, Arnaboldi O, Maiorana C, et al. (2015) Zirconia Implants in Esthetic Areas: 4-Year Follow-Up Evaluation Study. International Journal of Dentistry p. 1-8.

10. Patil R (2015) Zirconia versus titanium dental implants: A systematic review. Journal of Dental Implants 5(1): 39-42.

11. Cho Y, Shin J, Kim H, Gerelmaa M, Yoon H, et al. (2014) Comparison of the Osteogenic Potential of Titanium- and Modified Zirconia-Based Bioceramics. International Journal of Molecular Sciences 15(3): 44424452.

12. Pjetursson BE, Thoma D, Jung R, Zwahlen M, Zembic A (2012) A systematic review of the survival and complication rates of implantsupported fixed dental prostheses (FDPs) after a mean observation period of at least 5 years. Clinical Oral Implants Research 23: 22-38.

13. Oliva JD, Oliva J, Oliva X (2007) One-year follow up of first consecutive 100 zirconia Dental Implants in Human: A comparison of different rough surfaces. Int J Oral Maxillofacial Implants 22(3): 430-435.

14. Hashim D, Cionca N, Courvoisier DS, Mombelli A (2016) A systematic review of the clinical survival of zirconia implants. Clinical Oral Investigations 20(7): 1403-1417.

15. Borgonovo AE, Censi R, Vavassori V, Dolci M, Calvo-Guirado JL, et al. (2013) Evaluation of the Success Criteria for Zirconia Dental Implants: A Four-Year Clinical and Radiological Study. International Journal of Dentistry 1-7.

16. Saini M (2015) Implant biomaterials: A comprehensive review. World Journal of Clinical Cases 3(1): 52-57.

17. Setzer FC, Kim S (2014) Comparison of Long-term Survival of Implants and Endodontically Treated Teeth. Journal of Dental Research 93(1): 1926.

18. Karoussis IK, Salvi GE, Heitz-Mayfield LJ , Bragger U, Hammerle CH, et al. (2003) Long-term implant prognosis in patients with and without a history of chronic periodontitis: a 10-year prospective cohort study of the ITIR Dental Implant System. Clinical Oral Implants Research 14(3): 329-339. 
19. Misch CE, Perel ML, Wang H, Sammartino G, Galindo-Moreno P, et al. (2008) Implant Success, Survival, and Failure: The International Congress of Oral Implantologists (ICOI) Pisa Consensus Conference. Implant Dentistry 17(1): 5-15.

20. Gaviria L, Salcido JP, Guda T, Ong JL (2014) Current trends in dental implants. Journal of the Korean Association of Oral and Maxillofacial Surgeons 40(2): 50-60.

21. Sabir M, Alam MN (2015) Survival of Implants in Immediate Extraction Sockets of Anterior Teeth: Early Clinical Results. Journal of Clinical and Diagnostic Research : JCDR 9(6): 58-61.

22. Karoussis IK, Brägger U, Salvi GE, Bürgin W, Lang NP (2004) Effect of implant design on survival and success rates of titanium oral implants: a 10-year prospective cohort study of the ITI ${ }^{\circledR}$ Dental Implant System. Clinical Oral Implants Research 15(1): 8-17.

23. Karthik K, Sivakumar Sivaraj, Thangaswamy V (2013) Evaluation of implant success: A review of past and present concepts. Journal of Pharmacy \& Bioallied Sciences 5(1): 117-119.

24. Osman R, Swain M (2015) A Critical Review of Dental Implant Materials with an Emphasis on Titanium versus Zirconia. Materials 8(3): 932-958.

25. Papaspyridakos P, Chen CJ, Singh M, Weber HP, Gallucci GO (2011) Success Criteria in Implant Dentistry: A Systematic Review. Journal of Dental Research 91(3): 242-248.

26. Zembic A, Philipp AOH, Hämmerle CHF, Wohlwend A, Sailer I (2015) Eleven-Year Follow-Up of a Prospective Study of Zirconia Implant Abutments Supporting Single All-Ceramic Crowns in Anterior and Premolar Regions. Clinical Implant Dentistry and Related Research 17(2): 417-426.
27. Oshida Y, Tuna EB, Aktören O, Gençay K (2010) Dental Implant Systems. International Journal of Molecular Sciences 11(4): 1580-1678.

28. Cionca N, Müller N, Mombelli A (2014) Two-piece zirconia implants supporting all-ceramic crowns: A prospective clinical study. Clinical Oral Implants Research 26(4): 413-418.

29. Karoussis IK, Salvi GE, Heitz-Mayfield LJA, Brägger U, Hämmerle CHF, et al. (2003) Long-term implant prognosis in patients with and without a history of chronic periodontitis: a 10-year prospective cohort study of the ITI ${ }^{\circledR}$ Dental Implant System. Clinical Oral Implants Research 14(3): 329-339.

30. Osman RB, Elkhadem AH, Ma S, Swain MV (2013) Titanium Versus Zirconia Implants Supporting Maxillary Overdentures: ThreeDimensional Finite Element Analysis. The International Journal of Oral \& Maxillofacial Implants 28(5): 329-339.

31. Salinas T, Eckert S (2010) Implant-Supported Single Crowns Predictably Survive to Five Years with Limited Complications. Journal of Evidence Based Dental Practice 10(1): 56-57.

32. Le M, Papia E, Larsson C (2015) The clinical success of tooth- and implant-supported zirconia-based fixed dental prostheses. A systematic review. Journal of Oral Rehabilitation 42(6): 467-480.

33. Daou EE (2014) The Zirconia Ceramic: Strengths and Weaknesses. The Open Dentistry Journal 8: 33-42.

34. Grassi F, Capogreco M, Consonni D, Bilardi G, Buti J, et al. (2015) Immediate Occlusal Loading of One-Piece Zirconia Implants: Five-Year Radiographic and Clinical Evaluation. The International Journal of Oral \& Maxillofacial Implants 30(3): 671-680.

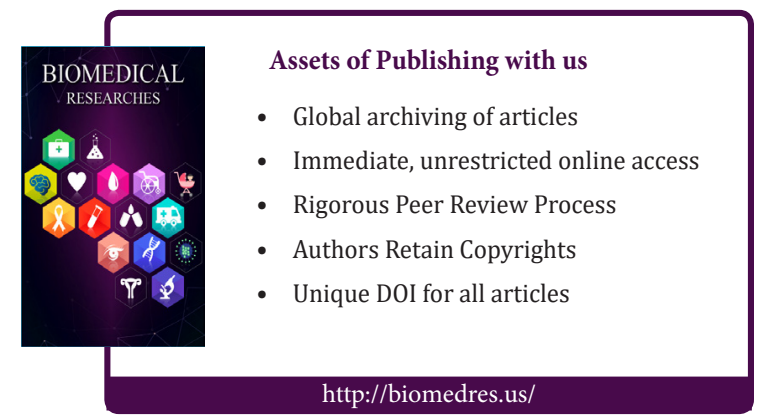

